\title{
Polyphenol Content and Antioxidant Effects in Herb Teas
}

\author{
Shizuo Toda \\ Department of Health Sciences, Kansai University of Health Sciences, Osaka, Japan \\ E-mail: toda@kansai.ac.jp \\ Received September 22, 2010; revised November 4, 2010; accepted December 22, 2010
}

\begin{abstract}
Herb teas, Arabian jasmine, Balsam pear, Barley grass, Guava, Hardy rubber tree, Japanese persimmon, Jobs tears, Oolong tea, Puerh tea and Wolofberry have been consumed as beverages for health in Asia. Oxidative stress induces various diseases. Some of them, Arabian jasmine, Guava, Hardy rubber tree, Japanese persimmon, Oolong tea and Puerh tea, have high total polyphenol content and antioxidant activities. Herbs and herbal polyphenols pay in controlling oxidation and prevent the damage by oxidation. These results showed that some of them, Arabian jasmine, Guava, Hardy rubber tree, Japanese persimmon, Oolong tea and Puerh tea, have high total polyphenol content and antioxidant activities. It has been demonstrated that high total polyphenol content in the herb teas provides high antioxidant activities.
\end{abstract}

Keywords: Antioxidant Effect, Herb Tea, Polyphenol

\section{Introduction}

Reactive oxygen species and free radicals induce oxidative stress. Oxidative stress is related to acute lung injury, acute respiratory distress syndrome and hyperoxia, aging, cardiovascular diseases as hypertension and myocardial infarction, cancer, diabetes, eye disease as age-related macular degeneration, immune diseases as inflammation and autoimmune disease, kidney disease, liver disease, neurological diseases as Alzheimer's disease, Hungtington's disease and Parkinson's disease, and pancreatitis [1-3].

The antioxidant pays in controlling oxidation and prevents the oxidation induced damage. They are, aminoacid (N-acetyl cysteine, L-arginine, glutathione, glycine, histidine, taurine and thiols), enzyme (catalase and superoxide dismutase), mineral (copper, iron, selenium, zinc), natural product (allicin, anthocyanin, biochanin A, carotenoids, cucumin, ellagic acid, epigallocatechin-3-Ogallate, flavonoids, glucosinolates, naringin, phyytic acid, polyphenol, querecetin), protein (alubumin, billrubin, ceruloplasmin, glutathione, lactoferrin, thioredoxin and transferrin), vitamine (nicotinamide, retinol, riboflavin, vitamin $C$, vitamin $E$ ), and urate [1-4].

Herbs have been consumed for food and medicinal purposes. They have a wide variety of active phytochemicals, including allicin, anthocyanin, biochanin A, carotenoids, coumarins, curcumins, ellagic acid, epigallocatechin-3-O-gallate, flavonoids, lignans, phthalides, phytic acid, plant sterols, polyphenols, saponins, sulfides and terpenoids. They contain potent antioxidant compounds, prevent odidative stress and provide significant protection against chronic diseases [5,6].

Tea is a rich source of polyphenolic flavonoids which exhibits potent antioxidant activity in vitro and in vivo. The polyphenolic flavonoid content of tea depends upon the type and preparation method. Randomized clinical examining the effect of tea on putative intermediary biomarkers suggest a potential health benefit from tea consumption [7].

Herb teas, Arabian jasmine, Balsam pear, Barley grass, Guava, Hardy rubber tree, Japanese persimmon, Jobs tears, Oolong tea, Puerh tea and Wolofberry have been consumed beverages for health in Asia, and especially Japan.

This article investigats total polyphenol content and antioxidant activities of these herb teas were investigated.

\section{Materials and Methods}

\subsection{Materials}

The tested herbs, Arabian jasmine, Balsam pear, Barley grass, Chameleon plant, Guava, Hardy rubber tree, Japanese persimmon, Jobs tears, Oolong tea, Puerh tea and Wolofberry, were from Yamamoto Kampo Co. (Aichi, Japan). They were of commercial grade. 
Ascorbic acid, glutathione and tannic acid were purchased from Wako Pure Chemicals Co. (Osaka, Japan). PAO-antioxidant assay kit was purchased from Japan Institute for the Control of Aging (Shizuoka, Japan). Other common laboratory reagents were of analytical grade.

\subsection{Preparation of the Herb Tea-Water Extract}

$1 \mathrm{~g}$ of the tested herb was extracted with $20 \mathrm{~mL}$ of hot water and stirred for $20 \mathrm{~min}$. The water extract was filtered. The filtrate was allowed to stand at $25^{\circ} \mathrm{C}$. The filtrate was diluted to $1 \%$ with water as test sample.

\subsection{Determination of Total Polyphenol Content}

The total polyphenol content of the water extract was determined by the Folin-Ciocallteu colorimetric method [8]. $0.5 \mathrm{~mL}$ tested sample was mixed with $0.5 \mathrm{~mL}$ of Folin-Ciocallteu reagent and $0.5 \mathrm{~mL}$ of $10 \%$ sodium carbonate solution. After mixture was incubated at room temperature for $1 \mathrm{~h}$, the absorbance was measured at 760 $\mathrm{nm}$. The total polyphenol was expressed as $\mathrm{mg} / \mathrm{g}$ tannic acid equivalent.

\subsection{Antioxidant Assay}

The antioxidant activity of test sample was assayed by PAO-antioxidant assay kit (Japan Institute for the Control of Aging, Shizuoka, Japan). The antioxidant activity was $\mathrm{mmol} / \mathrm{L}$ as copper reducing power [9].

\subsection{Statistical Analysis}

The values were expressed by the means of \pm standard deviation (SD) of five experiments. The results were analyzed by the nonparametric analysis of variance (ANOVA)- Scheffe $F$-test.

\section{Results}

Table 1 shows the total polyphenol content of the herb tea-water extract. The total polyphenol content of Arabian jasmine, Guava, Hardy rubber tree, Japanese persimmon, Oolong tea and Puerh tea-water extract was more than that of others.

Table 2 shows the results of antioxidant assay. The antioxidant activities of Arabian jasmine, Guava, Hardy rubber tree, Japanese persimmon, Oolong tea and Puerh tea-water extract were higher than those of others at 50.0 $\mathrm{mg} / \mathrm{mL}$ of the herb tea-water extract. The antioxidant activities of ascorbic acid and glutathione are $11.38 \pm$ 1.76 and $2.63 \pm 1.27 \mathrm{mmol} / \mathrm{mM}$ at $1.0 \mathrm{mM}$ of those rea- gents.

\section{Discussion}

Herbal medicines have been consumed and played an important role in the world. Wargovin demonstrated that the widespread use of herbs either directly or indirectly supplements, may prevent cancer, and help health promotion [10]. The tested herbs, Arabian jasmine, Balsam pear, Barley grass, Hardy rubber tree, Japanese persimmon, Jobs tears, Oolong tea, Puerh tea and Wolofberry, were consumed as beverages for health in Asia.

Green tea polyphenols, epicatechin, epigallocatechin gallic acid and epigallocatechin gallate inhibit production of oxidative stress. Oxidative stresses induce various diseases, heart disease, renal disease and failure, skin

Table 1. Total polyphenol content of herb tea-water extract.

\begin{tabular}{lc}
\hline Herb tea-water extract & Total polyphenol content $(\mathrm{mg} / \mathrm{g})$ \\
\hline Arabian jasmine & $101.2 \pm 17.8$ \\
Balsam pear & $14.5 \pm 2.6$ \\
Barley grass & $10.5 \pm 1.5$ \\
Guava & $83.0 \pm 5.9$ \\
Hardy rubber tree & $43.4 \pm 4.8$ \\
Japanese persimmon & $41.3 \pm 6.7$ \\
Jobs tears & $4.2 \pm 1.4$ \\
Oolong tea & $120.9 \pm 14.8$ \\
Puerh tea & $40.4 \pm 7.2$ \\
Wolofberry & $17.1 \pm 4.2$ \\
\hline
\end{tabular}

The Total polyphenol content of the herb tea-water extract was determined by Folin-Ciocallteu colorimetric method. The value was expressed as the mean $\pm \mathrm{SD}$ of five experiments.

Table 2. Antioxidant activity of herb tea-water extract.

\begin{tabular}{lc}
\hline Herb tea-water extract & Antioxidant activity \\
\hline Arabian jasmine & $144.0 \pm 1.4 \mathrm{mmol} / \mathrm{L}$ \\
Balsam pear & $19.7 \pm 2.4 \mathrm{mmol} / \mathrm{L}$ \\
Barley grass & $9.2 \pm 0.5 \mathrm{mmol} / \mathrm{L}$ \\
Guava & $172.5 \pm 2.0 \mathrm{mmol} / \mathrm{L}$ \\
Hardy rubber tree & $45.5 \pm 2.3 \mathrm{mmol} / \mathrm{L}$ \\
Japanese persimmon & $65.7 \pm 1.8 \mathrm{mmol} / \mathrm{L}$ \\
Jobs tears & $7.4 \pm 1.7 \mathrm{mmol} / \mathrm{L}$ \\
Oolong tea & $184.8 \pm 2.7 \mathrm{mmol} / \mathrm{L}$ \\
Puerh tea & $59.1 \pm 2.2 \mathrm{mmol} / \mathrm{L}$ \\
Wolofberry & $20.1 \pm 0.7 \mathrm{mmol} / \mathrm{L}$ \\
Ascorbic acid & $139.7 \pm 0.5 \mathrm{mmol} / \mathrm{L}$ \\
Glutathione & $76.6 \pm 9.5 \mathrm{mmol} / \mathrm{L}$ \\
\hline
\end{tabular}

The antioxidant activity of test sample was assayed by PAO-antioxidant assay kit. The value was expressed as the mean \pm SD of five experiments. 
exposure damage caused by ultraviolet rays, and diseases associated with aging. Green tea polyphenols have antioxidant effects, such as cancer prevention and inhibition, obesity and weight controlling. [11]. The daily intake of polyphenol has been showed $\sim 1 \mathrm{~g} / \mathrm{d}$. given diet including some common fruits, vegetables and beverages [12].

The presented herb teas have various effects [13-22]. Tables 1 and $\mathbf{2}$ show that some of them, Arabian jasmine, Guava, Hardy rubber tree, Japanese persimmon, Oolong tea and Puerh tea, have high total polyphenol content and antioxidant activities.

These results demonstrated that the high total polyphenol content in the herb teas provides high antioxidant effects.

\section{References}

[1] T. Iannitti and B. Palmier, "Antioxidant Therapy Effectiveness: An Up to Date,” European Review for Medical and Pharmacological Sciences, Vol. 13, 2009, pp. 245278.

[2] J. K. Willcox, S. L. Ash and G. L. Catignani, "Antioxidants and Prevention of Chronic Disease," Clinical Review in Food Science Nutrition, Vol. 44, No. 4, 2004, pp. 275- 295. doi:10.1080/10408690490468489

[3] I. S. Young and J. V. Woodside, 2001. "Antioxidants in Health and Disease,” Journal of Clinical Pathology, Vol. 54, No. 3, 2001, pp. 176-186. doi:10.1136/jcp.54.3.176

[4] S. Vertuani, A. Angusti and S. Manfredini, "The Antioxidants and Pro-Antioxidants Network: An Overview," Current Pharmaceutical Design, Vol. 10, 2004, pp. 16771694. doi:10.2174/1381612043384655

[5] H. Barlett and F. Eperjesi, “An Ideal Ocular Nutritional Supplement?” Ophthalmic Physiological Optics, Vol. 24, No. 4, 2004, pp. 339-349. doi:10.1111/j.1475-1313.2004.00218.x

[6] W. J. Craig, "Health-Promoting Properties of Common Herbs,” American Journal of Clinical Nutrition, Vol. 70 (Supp.), No. 3, 1999, pp. 491-499.

[7] D. L. Mckay and J. B. Blumberg, "The Role of Tea in Human Health: An Update," Journal of the American College of Nutrition, Vol. 21, No. 1, 2002, pp. 1-13.

[8] S. Toda, “Antioxidative Effects of Polyphenols in Leaves of Houttuynia Cordata on Protein Fragmentation by Copper-Hydrogen Peroxide in vitro," Journal of Medicinal Food, Vol. 8, No. 2, 2005, pp. 266-268. doi:10.1089/jmf.2005.8.266

[9] K. Sasaki, S. Kino, M. Takeuchi, T. Ochi, G. D. Cruz and I. Tomita, "Analysis of Antioxidant Activities in Vegetable Oils and Fat Soluble Vitamins and Biofactors by the PAO- SO Method," Methods Molecular in Biology, Vol. 594, Part 2, 2010, pp. 241-250. doi:10.1007/978-1-60761-411-1_16

[10] M. J. Wargovichi, C. Woods, D. M. Hollis and M. E. Zander, "Herbals, Cancer Prevention and Health,” Jour- nal of Nutrition, Vol. 131, No. 11, 2001, pp. 3034-3036.

[11] B. Frei and J. V.Higdon, "Antioxidant Acitivity of Tea Polyphenols in Vivo: Evidenmce from Animal Studies," Journal of Nutrition, Vol. 133, No. 10, 2003, pp. 32753284.

[12] A. Scalbert and G. Williamson, "Dietery Intake and Bioavailability of Polyphenols,” Journal of Nutrition, Vol. 130, No. 8, 2000, pp.2073-2085.

[13] N. Inoue, K. Kuroda, A. Sugimoto, T. Kakuda and T. Fushiki, "Autonomic Nervous Responses According to Preference for the Odor of Jasmine Tea,” Biosicience Biotechnology and Biochemistry, Vol. 67, No. 6, 2003, pp. 1206- 1214. doi:10.1271/bbb.67.1206

[14] L. Harinantenaina, M. Tananka, S. Takaoka, M. Oda, O. Mogami, M. Uchida and Y. Asakawa, "Momordica Charantia Constituents and Antidiabetic Screening of the Isolated Major Compounds," Chemical and Pharmaceutical Bulletin, Vol. 54, No. 7, 2006, pp. 1017-1021. doi:10.1248/cpb.54.1017

[15] N. P. Ames and C. R. Rhymer, "Issues Surrounding Health Claims for Barley,” Journal of Nutrition, Vol. 138, 2008, pp. 1237-1243.

[16] T. Matsuura, Y. Yoshikawa, H. Masui and M. Sano, "Suppression of Glucose Absorption by Various Health Teas in Rats,” Yakugaku Zasshi, Vol. 124, No. 4, 2004, pp. 217-223. doi:10.1248/yakushi.124.217

[17] T. Namba, M. Hattori, J. N. Yie, Y. H. Ma, Y. Nomura, S. Kaneko, Y. Kitamura, T. Koizumi, K. Katayama and W. Lu, 1986. "Tu-Chung Leaves (I), Pharmacological Effects of the Water Extract in Vivo," Journal of Traditional Medicine, Vol. 3, 1986, pp. 89-97.

[18] T. Tanaka, "Chemical Studies on Plant Polyphenols and Formation of Black Tea Polyphenols,” Yakugaku Zasshi, Vol. 128, No. 4, 2008, pp. 1119-1131. doi:10.1248/yakushi.128.1119

[19] Y. Lu, C. Li and Q. Dong, “Chinese Herb Related Molecules of Cancer-Cell-Apoptosis: A Minireview of Progress between Kanglatie Injection and Related Genes,” Journal of Experimental \& Clinical Cancer Research, Vol. 27, 2008, p. 31. doi:10.1186/1756-9966-27-31

[20] T. Komatsu, M. Nakamori, K. Komatsu, K. Hosoda, M. Okamura, K. Toyama, Y. Ishikura, T. Sakai, D. Kunii and S. Yamamoto, "Oolong Tea Increases Energy Metabolism in Japanese Females,” Journal of Medical Investigation, Vol. 50, pp. 170-173.

[21] P. D. Duh, W. J. Yen, B. S.Wang and L.W. Chang, "Effects of Pu-Erh Tea on Oxidative Damage and Nitric Oxide Scavenging,” Journal of Agricultural and Food Chemistry, Vol. 52, No. 26, 2004, pp. 8169-8176. doi:10.1021/jf0490551

[22] O. Potterat, 2010. “Goji (Lycium Barbarum Nad L. Chiense): Phytochemistry, Phar, Macology and Safety in the Perspective of Traditional Uses and Recent Popularity,” Planta Medica, Vol. 76, No. 1, 2010, pp. 7-19. doi:10.1055/s-0029-1186218 